\title{
POLITICAL CORRECTNESS IN BUSINESS COMMUNICATION
}

\author{
Anamaria-Mirabela Pop, Monica-Ariana Sim \\ Department of International Business, Faculty of Economic Sciences, University of \\ Oradea, Oradea, Romania \\ mipop@uoradea.ro \\ arianamona@yahoo.com
}

\begin{abstract}
In a world increasingly trying to erase past inequalities and discriminations, words must communicate intent as much as ideas. We live in politically correct cultures, where unspoken rules of respectability govern conduct in cross-cultural interactions, meaning interactions among people of different races, genders, or religions. Therefore, it is essential to use politically correct language to avoid offending the audience. Even if it is not intended, failing to do so can have devastating effects professionally and personally. As it is frequently seen in the media, writing or speaking without using politically correct or inclusive language can have a negative impact that proves impossible to take back, especially in today's age of social media and online content sharing. Politically correct means expressing yourself using neutral, unbiased, and inoffensive language that does not degrade, demoralize, or discriminate against another person or group. Inclusive language considers all perspectives without exclusion, inferiority, or stereotyping. Conspicuous prejudice and discrimination in the workplace are far less acceptable today. Laws now protect traditionally underrepresented groups from flagrant discrimination in hiring and promotion, and political correctness has reset the standards for politeness and respect in people's daily interactions. Yet, in spite of the progress mentioned, political correctness is an equivocal term. While it has helped many traditionally underrepresented employees to experience their workplace as more inclusive, the rules of political correctness can prevent employees from developing effective relationships across differences that might divide groups. The paper attempts to analyze the rise and enforcement of political correctness rules related to the ongoing economic processes in the new economy of the world. In this new economy, the organizational boundaries between states and firms become unclear and, apart from conceiving a new vocabulary able to express the changes the firms are undergoing, when speaking or writing, all members of the audience should be included and addressed using inclusive language.
\end{abstract}

Keywords: political correctness; business communication; vocabulary; discriminatory language

JEL Classification: Z19

\section{Introduction: The History of Political Correctness}

In recent years and decades, we have been paying more attention to our words. Society, in general, has been moving towards non-discriminatory language. How did this come about? Why do we consider some words more ethic than others? No society has ever permitted total freedom of speech without any restrictions whatsoever and it is hard to see how it could. Therefore, in the contemporary world there are many restraints on free speech. A large number of employers place restrictions on their employees' freedom to speak about their work or to go to the press. For instance, a woman who would like to become a partner in a company does not say anything when she is ignored even though she knows she is perfectly capable of becoming one for fear of not confirming the notion that women do not have what it takes to become partner. Or a coloured individual passed over for promotion might wonder 
whether his race has anything to do with it, yet he is reluctant to raise this concern because he would be perceived as the one "playing the race card. These restrictions are usually presented as matters of respect for authority, or not bringing the company into dispute or just good manners, but they remain restrictions on freedom of speech nonetheless.

The idea of political correctness (abbreviated to $P C$ ) has received a lot of attention for many years now. The term is typically associated with the "censorship of policies, actions and language" (Kaufman, 2016) seen to disadvantage or offend a particular group of people in society, and the development of ways to fix such social injustices.

According to predominantly conservative critics of what they call the "political correctness movement," the term involves, again, censorship and social engineering, and has influenced popular culture, such as music, film, literature, arts and advertising. The term "political correctness" is often used to ridicule either the idea that carefully chosen language can promote certain social advantages and relationships, or the belief that the resulting changes benefit society.

Yet, on the other hand, according to Messer-Davidow (1993), the term "political correctness" is part of a larger attack on social equality or political progressivism. People using the term in this sense argue that expressing an opinion about the use of language cannot in itself represent intolerance or censorship. Also, there is a concern expressed by those who use the term in a derogatory fashion regarding the "potential dilution of speech and the failure to express important problems concerning the society." (Pop, 2013) They claim that people's freedom of speech might be inhibited, people being afraid that when expressing their opinions they might offend some group.

The term "political correctness" proves quite difficult to define. The definition of politically correct language might relate to words that focus on empathy, fairness and justice. Words and phrases that have been accepted and entered into our day to day vocabulary that enhance the inclusion of individuals or groups of people, usually found in minorities in our societies and communities. Noam Chomsky at some time defined it as a "healthy expansion of moral concern" (Allan and Burridge, 2007:90).

The phrase "politically correct" actually emerged approximately 50 years ago. However, it once appears in a U.S. Supreme Court decision in 1793, within the context of the case 'Chrisholm v. Georgia' wherein Justice James Wilson points out that it is not politically correct to say the "People of the United States" as this should be replaced with "The United States" (Allan and Burridge, 2007:90) instead. Even though this is a proof that the term "political correctness" appeared early in the language, in fact, it was rarely used until the 1960s. Other claim that during that time period it may have been adapted by the American New Left from former Soviet and Chinese ideological speak in which the term indicated whether the members followed the ideologies of the party (Perry,1992:90). Thus, in the 1960s and 1970s, the term "political correctness" acquired a rather negative connotation; it was used to refer to the fellow members of one's party "who toed the party line very strictly and whose behaviour was therefore seen as 'ultra-correct"' (Goddard and Patterson, 2000:69).

Ely, Meyerson, and Davidson (2006) define political correctness as a situation "where unspoken canons of propriety govern behaviour in cross-cultural interactions-that is, interactions among people of different races, genders, religions, and other potentially charged social identity groups".(p.1) Compared to the current definition of the term, it becomes sufficiently clear that it does not possess the same meaning any longer. The conservatives transformed the notion of "political correctness" to pretend that "a left-wing movement based in liberal academic circles was trying to create a new doctrinaire political orthodoxy through social engineering which included changing words and phrases that some groups found offensive." (Pop, 2013:7)

The late of the 1990s saw a decline in the use of the term. Yet, we can state that, nowadays, it is both an active behaviour as well as an intentional avoidance of using words and 
expressions which could imply "a sense of exclusion and marginalization of people who are considered to be socially disadvantaged or discriminated against." (Tokarev, 2016)

Moreover, words that were commonly used in the past are nowadays completely out as many organizations and authorities have also come up with language, policies, and measures that are considered as alternatives to discriminatory words and always adding to the ever-growing politically correct language list.

\section{Political Correctness - A Double-Edged Sword}

Cultural diversity in particular is essential to one's growth, ability to solve problems and to innovate. But, quite often, when faced with diversity the unconscious judgment of others who appear different makes it all but impossible for one to collaborate and solve problems. The more judgmental one is the more fundamentalist he/she is.

Through the avoidance of challenging topics (political correctness) it has been created an environment that hinders people's ability to live and work comfortably with those who are different from them. Political correctness has probably become a bigger problem than the problem it was intended to address. On the one hand, it has helped make societies more unprejudiced by pushing them away from offensive stereotypes and discriminatory language. Political correctness has certainly made some positive contributions to the pursuit of social equality. The use of PC language has helped people shift away from discriminatory speech, for example. The PC focus on language and naming has also helped improve the visibility of people's natural diversity, which has resulted in the productive strive for better and more accurate representation of human experiences. Collectively, these changes benefit all people because they help improve society by making the treatment of everyone in it more equal.

On the other hand, it has led to new obstacles by increasing in-group hostilities and reducing opportunities for dialogue and mutual understanding. First of all, meaning is subjective and constantly changing. As Kai Sherwi (2017) argues, some thoughts, phrases, and actions are "correct" while others are not creating an ever-tightening noose around the freedom of speech and expression. The columnist states that no matter how uncomfortable people are with inflammatory language or actions, it is crucial to recognise it as a small price to pay to maintain a democratic system that promotes free expression as a basic pillar of society.

Therefore, it is not surprising that PC discourse has led to in-group hostility. Focusing on politically correct language has encouraged the practice of being constantly aware of another's speech, perhaps most noticeably amongst members of the same community. Thus, in business, this practice has resulted in the transformation of what were initially intended to be "safe spaces" into hostile environments, which is not only counterproductive, but also affects the atmosphere where these people/ employees are supposed to spend quality time, contributing to the welfare of the company.

\section{Political Correctness and Business}

When talking about political correctness at the work place, one might wonder how people can be authentic and productive if they are constantly worried about offending their colleagues through language that could be perceived as offensive. Some people consider political correctness a necessary social norm as it can keep workplaces civil and employers safe from lawsuits. Others consider political correctness a threat on productivity, thus hindering creativity and free speech.

There have been voices worrying that political correctness suppresses free speech throughout the media for decades. Also, there have been many books written on how PC culture negatively affects everything from enterprise organizations to comic book conventions. It is a fact, that in the USA, for instance, according to a recent study, most Americans dislike PC culture and believe it is a problem in their country. (Mounk, 2018)

However, research actually shows that groups of people who have been exposed to PC culture come up with more innovative ideas than those who have not. According to a study carried out by Cornell University, researchers found that "by imposing a PC environment, 
they had made it easier for men and women to speak their minds in mixed company. They had 'reduced the uncertainty' that can come with interacting with someone from the opposite sex." (Demby, 2015)

In spite of the commitment to equity that underlies political correctness and the shifts in norms wrought by that commitment, there is still the concern regarding the barriers that political correctness can pose to developing constructive, engaged relationships at work. As an article in Harvard Business Review states, "I[i]n cultures regulated by political correctness, people feel judged and fear being blamed. They worry about how others view them as representatives of their social identity groups. They feel inhibited and afraid to address even the most banal issues directly. People draw private conclusions; untested, their conclusions become immutable. Resentments build, relationships fray, and performance suffers." (Ely et al, 2006)

\subsection{Business Communication. Rules of a Political Correct Business Communication}

Business communication is the process of sharing information between people within and outside a company. In the age of digital, global businesses, it is essential for organizations of all sizes to effectively communicate not only within their organization, but also with shareholders, vendors, clients, and customers. Effective communication is the basis of significant business processes and must be efficient so that personnel can successfully share and communicate information that helps to run a successful enterprise. Therefore, effective communication is critical for a business to operate efficiently. While budgets, operational procedures, project timelines, and the bottom/top line of an organization are often the focus of Board meetings, effective, honest, and ethical communication principles do not always receive the same level of focus. According to Blue Source, most employees $(97 \%)$ consider that communication has a real impact on everyday tasks. (https://www.bluesource.co.uk/20-astonishing-stats-business-communications/)

Therefore, effective business communication is a concrete principle that businesses need to apply on a daily basis. Statistics show that effective business communication has a significant effect on workplace productivity. Blue Source indicates that productivity goes up by 25 percent in businesses with connected and engaged personnel, and, at the same time, 44 percent of employees want more broad adoption of internal communication tools, suites, and apps. (https://www.bluesource.co.uk/20-astonishing-stats-business-communications/) This shows how important effective communication is in a business: the employees are able to work better and operate within a team in a more effective manner when good communication practices are used.

Today the business environment is flooded with people from different cultures and ethnicities. Today, when professionals address the reader, they are communicating with a mixed group of nationalities: people of different age groups, ethnicities, economic backgrounds, marital statuses, and genders.

Language is a reflection of the socio-cultural environment of any given society. Words, phrases, titles, and designations are derived from the prevailing conditions in a society. The English language as we know it today has evolved through the ages. Many of the words, titles, and phrases that were appropriate in yesterday communication are considered discriminatory now, as the society continues to rapidly change.

Recently, there have been attempts to broaden the concept of non-discriminatory language beyond its application to gender to consider traditional language that discriminates against people on the grounds of: race, ethnicity, religion, age, sexual orientation, physical ability or physical appearance.

Here are some common examples of politically correct terms that should be used in business communication:

\section{Gender related terms}


More and more women have entered the corporate world, causing a number of genderbiased terms to be inappropriate. Even so, gender discriminatory language is one of the most prominent pitfalls that professionals face when writing a business document. The following are some of the rules one needs to follow to keep one's business writing free of gender-discriminatory language.

a) Use neutral job titles

Professions that were considered male props are now open to both men and women, hence the terms and titles used to denote a certain profession ending in "man" have been revised. See the following examples: policeman -- police officer; mailman -- mail carrier; chairman -chair.

b) Use neutral salutations

If the recipient is unknown, neutral salutations should be used. If you do not know the gender of the recipient who will receive your communication, avoid opening your letter with "Dear Mr." or "Dear Gentlemen." In today's business environment, one cannot assume the sex of the recipient. A simple "To whom it may concern" will work well.

c) Avoid the use of masculine pronouns:

Generally, while speaking or writing, the masculine pronouns such as he, him, and his are used as a blanket term to refer to any group. In a mixed group, such blanket terms tend to negate the individuality of women. Since English does not have a third person, singular, gender-neutral pronoun, there are ways in which you can prevent this problem:

- use a gender-neutral term such as they, but make sure it matches a plural antecedent;

- $\quad$ avoid using any pronouns by redoing the sentence;

- $\quad$ use "he and/or she" following a singular noun;

- occupational nouns and titles - in the past, certain nouns and titles for occupations were created for women. More often than not, these titles were derived from their male counterparts. Today, these terms are not used anymore, as they imply women's dependence on men. Words like "actress," "waitress," "poetess," and "salesgirl" have been dropped from politically correct vocabulary.

\section{Derogatory terms}

Derogatory terms include words that tend or intend to play down, depreciate or denigrate and can often be considered offensive. Derogatory words have the power to hurt and potentially cause violence or other forms of hostility. The origins of these depreciating terms can depend on geographic location, history and culture of a particular region. The list of derogatory words based on religion, race, ethnicity, sex, colour and disability among others is growing as people find new words to categorize a particular group with the intent to demean or persecute. Derogatory terms are deep-rooted in our society. They can often be heard in the workplace, music, movies and social media. Referring to someone as "bitch," "redneck," "gay," "retarded," "nigga," or similar words while playfully joking around is still offensive. By using these terms, it associates members of a particular group with behaviour, beliefs or actions that are extremely negative. People can use these so called jokes or terms as a way of expressing how they truly feel.

a) Derogatory religious or racial terms

In a cross-cultural business environment, it can be damaging for somebody's professional reputation if they use words or phrases that have a derogatory connotation as far as religion or race goes. Language is what connects one human being to another; if one uses certain stereotypes in addressing or referring to someone, it can have a deep impact on the other person. Resentment, anger or pain are some of the feelings that people might experience if they are labelled a certain way. References to race, religion, or culture should be avoided in business communication. Terms such as "Blacks, "Japs," "Orientals," and "Jews" are not acceptable.

b) Derogatory terms for physical handicaps 
Terms such as "dumb," "crippled," "retarded," or even "handicapped" are considered offensive in today's world and should be avoided. Instead, using the term "person or persons with a disability" would be appropriate.

Jargon

According to Pop and Sim (2014), "professionals from different fields and academics are famous for their pervasive use of jargon, but they are not alone. Sometimes, employees use a great deal of jargon which is not part of the wider industry, but unique to that office environment. The reason is to use words shortened to make communication faster." (p.113) Jargon inadvertently occurs in a professional's communication. While it is fine to use it with readers who are part of the closed user group that understands that jargon, it is counterproductive to use jargon with a person who is not in the field. This alienates and puts off a reader. Not every person in the world would know what GDP or PoP is. The message is lost. For example, when using GDP, the writer should mention Gross Domestic Product in brackets for the benefit of the reader.

\section{Slang}

Slang is a type of language that is informal and playful. It often changes over time. The slang of the past is different than the slang of today, yet some slang has carried over into the present. Slang also varies by region and culture. The important thing to understand is that slang is casual talk, and it should be avoided using it in formal contexts. Slang is meant for informal communication and while talking to an informal group of people. Written business communications should never contain any form of slang. Written communications are usually created for customers, management, investors, or other more formal audiences. Using slang in business communication could cause the reader to not take the business seriously and could possibly have disastrous results.

Also, one has to consider that more modern slang terms may be misinterpreted or misunderstood by the reader. This could be due to age or someone who uses English as a second language. Thus, embarrassing situations should be avoided by leaving slang completely out of written documents and communications.

In the same time, if instant messaging is used in an office, then it is probably going to be difficult not to use some form of slang. Employees are most likely going to type instant messages similar to the way they text, as it is an informal way to communicate. The same situation applies to emails, but it might get a little bit more complicated in this case. If team members working on a project are emailing documents or information back and forth with each other, the emails will likely include varying degrees of slang. However, when those emails turn into progress reports or project updates addressed to upper management or outside parties, slang should be avoided. Also, slang must be never be used when emailing customers.

\section{Titles and naming practices}

Getting titles right in business correspondence is vital. It is best to address people by their full, correct title, no matter how extraordinarily long that title may seem to others. First names are reserved for family members and close friends. Until you are informed otherwise, or have developed a personal relationship, it is very important to refer to a counterpart with his or her title The title "Mr." immediately identifies the reader as a man. Titles for women are the sensible area. "Mrs." or "Miss" not only identifies the recipient as a woman but also are indicative of her marital status. In today's business world, the use of Mrs. or Miss has been dropped, unless a woman specifically asks to be addressed that way. Instead, the more neutral title "Ms." has been brought into use, or writing out the entire name, i.e., "Dear Alice Smith."

\section{In conclusion}

The world is becoming a more global environment. Workplaces exist without walls, individuals drift through borders, and true progress is seeing a world of humanity more than 
individual nations. In these times, some argue political correctness in the workplace is a good thing. Others say it has a negative effect on communication. But the fact is that in today's world of business, prejudices and discrimination are not acceptable. There are laws protecting people of different races and ethnicities from discrimination in hiring and promotion. In spite of that, there are voices arguing that political correctness might create a restrictive and fearful atmosphere at the workplace. Because of the rules governing the concept, the employees sometimes find difficult to develop effective relationships among themselves, cautiously tackling these issues.

It has been said that "political correctness" consumes resources by denying or delaying management attention from real problems. Businesses move forward because people focus on making the business better, not by being so much concerned about one's self-esteem.

There are many reasons for which the topic of political correctness in business communication deserves to be studied further in detail. There are voices saying that political correctness in itself has begun to isolate individuals. While the initial intention of political correctness was to reject derogatory terms in order to create more respect for one another, it has, in the end, made society more uncomfortable with people who fit the conditions of these politically charged terms.

\section{References}

1. Demby, G. (2015) "What Research Says About The Consequences Of PC Culture". Retrieved March 15,2021 [online] https://www.npr.org/sections/codeswitch/2015/01/30/382475295/what-researchsays-about-the-consequences-of-p-c-culture?t=1617459698664

2. Ely, R. J., Meyerson, D. E., \& Davidson, M. N. (2006) "Rethinking political correctness", Harvard Business Review. Retrieved April 6, 2021 [online] https://hbr.org/2006/09/rethinking-politicalcorrectness

3. Goddard, A.\& Patterson, L.M. (2000). Language and Gender. London, New York: Routledge.

4. Kai Sherwi, K. (2017) "Political Correctness: The Effects on Our Generation". Retrieved March 25, 2021 [online] https://www.huffpost.com/entry/political-correctness-the b 9600916

5. Kaufman, S.B. (2016) "The Personality of Political Correctness". Retrieved April 8, 2021 [online] https://blogs.scientificamerican.com/beautiful-minds/the-personality-of-political-correctness/

6. Keith, A. \& Burridge, K. (2007). Forbidden Words. Taboo and the Censoring of Language. Cambridge University Press.

7. Messer-Davidow, E. (1995). "Manufacturing the Attack on Liberalized Higher Education: The Humanities and Society in the 1990s." In C. Newfield, \& R. Strickland (Eds.), After Political Correctness: The Humanities and Society in the 1990s (pp. 38-78). Westview.

8. Mounk, Y. (2018) “Americans Strongly Dislike PC Culture”. Retrieved March12, 2021. [online] https://www.theatlantic.com/ideas/archive/2018/10/large-majorities-dislike-politicalcorrectness $/ 572581 /$

9. Perry, R. (1992). "A Short History of the Term 'Politically Correct"'. In Patricia Aufderheide, P. (ed.) Beyond PC: Toward a Politics of Understanding. Graywolf Press.

10. Pop, A.M. (2013) Business Buzzwords and Political Correctness, Lambert Academic Publishing. 11. Pop, M., Sim, M. (2014) "Business English Outside the Box. Business Jargon and Abbreviations in Business Communication". Annals of the University of Oradea, Economic Sciences Fascicle. Retrieved April 4, 2021. [online] http://anale.steconomiceuoradea.ro/volume/2014/AUOES-2-2014.pdf 12. Tokarev, V. (2016) "Political Correctness. Language Change from Above", Munich, GRIN Verlag. Retrieved March 18, 2021. [online] https://www.grin.com/document/382469)

13. "20 astonishing stats about business communications". Retrieved April 2, 2021 [online] https://www.bluesource.co.uk/20-astonishing-stats-business-communications/ 